\title{
SOLIDARIDAD ANTE LA ADVERSIDAD: ALGUNOS EJEMPLOS DE LA RESISTENCIA DE LOS JESUITAS ESPAÑOLES Y SU ENTORNO SOCIAL CONTRA LA POLÍTICA ANTIJESUITA DEL MARQUÉS DE POMBAL (1759-1768)*
}

\author{
MAR García Arenas \\ Universidad de Alicante
}

Fecha de recepción: noviembre 2012

Fecha de aceptación: abril 2013

El 3 de septiembre de 1759 se promulgaba el decreto de expulsión de los jesuitas de todos los dominios de la monarquía portuguesa ${ }^{1}$. El destino de cerca de mil ochenta y dos jesuitas expulsados, ente 1759 y 1767, fue el exilio en los Estados Pontificios ${ }^{2}$, según los catálogos de la Compañía ${ }^{3}$, si bien el P. António Trigueiros rebaja esa cifra a mil treinta y seis ${ }^{4}$.

\footnotetext{
* La elaboración de este trabajo ha sido posible gracias a la concesión de una beca postdoctoral del programa Vali $+\mathrm{d}$ de la Generalitat Valenciana, con la referencia Apostd/2012/048, para desarrollar el proyecto: La represión del jesuitismo por el marqués de Pombal y la apologética jesuita: instrumentos, alcances, repercusión e influencias en la Europa de la segunda mitad del setecientos.

Una aproximación a esta cuestión fue abordada en nuestra tesis doctoral: La cuestión jesuita en las relaciones diplomáticas hispano-portuguesas (1759-1773), dirigida por el Dr. Enrique Giménez López y galardonada con el premio Luis Diez del Corral 2012, concedido por el Centro de Estudios Políticos y Constitucionales, dependiente del Ministerio de la Presidencia.

1. Hay una exhaustiva recopilación bibliográfica sobre este asunto en Biblioteca Nacional de Portugal (Org.): A expulsão dos jesuitas dos dominios portugueses. $250^{\circ}$ aniversário. Lisboa, 2009. Un compendio de las relaciones entre Pombal y la Compañía de Jesús se puede consultar Monteiro, Miguel Corrêa: «Pombal e os Jesuítas», en Jesuitas, utopia e realidade. Lisboa, Academia Portuguesa da História, 2011, pp. 71-94.

2. Para conocer un ejemplo de cómo se vivió ese exilio Monterro, Miguel Corrêa: Inácio Monteiro (17241812). Um jesuita portugués na dispersão. Centro de História da Universidade de Lisboa, Lisboa, 2004.

3. En el Archivium Romanun Societatis Iesu de Roma, sección Lusitania, en adelante, ARSI, Lus. 41. Nota de los sujetos de la Asistencia de Portugal y el número y desembarco a Civitavecchia.

4. Trigueiros, António: «I gesuiti portoghesi espulsi in Italia: vita e cultura nei quattro convitti italiani», en Ugo Baldini y Gian Paolo Brizzi (Coord.): La presenza in Italia dei gesuiti iberici espulsi. Aspetti religiosi, policiti, culturali., CLUEB, Bolonia, 2010, pp. 57-74.
} 
Sin embargo, no todos los regulares tuvieron como destino el exilio en Italia, pues un gran número de ellos, entre los que se encontraban todos los religiosos extranjeros, varios procedentes de ultramar y los que ostentaron cargos dentro de la jerarquía ignaciana, se quedaron en Portugal, confinados en conventos, en casas de campo habilitadas como prisiones, Azeitão ${ }^{5}$, y también en presidios como el castillo de São Jorge, los fuertes de la Junqueira, Almeida, Pedrouços y São Julião, o la cárcel pública de Belem. El número de jesuitas que fueron encarcelados constaba de un total de doscientos veintidós religiosos, de los cuales más de ochenta morirían en las cárceles, treinta y nueve fueron liberados en 1767 para marchar a Italia con el resto de sus compañeros de religión y el resto lo serían en 1777 a la muerte de José $\mathrm{I}^{6}$.

Las noticias del infortunio al que se vieron sometidos estos prisioneros fueron conocidas en Europa a través de una variada correspondencia clandestina. El mérito de que las epístolas llegasen a sus destinos recayó en los correos, seglares leales a la Compañía de Jesús. No hay que olvidar el gran ascendiente de la Compañía sobre amplias capas de la sociedad, pues los jesuitas no sólo contaban con partidarios procedentes de sus aulas, en virtud de su monopolio sobre la enseñanza media y en los colegios mayores, sino también de aquellos individuos vinculados a la Compañía por cartas de hermandad ${ }^{7}$, pertenecer a sus congregaciones ${ }^{8}$ o por ser los padres sus guías espirituales. La fidelidad que estas personas profesaban a los jesuitas no era baladí, pues el socorro a los regulares podía suponer graves castigos como la confiscación de sus bienes, el destierro, la prisión, las temidas galeras e, incluso, la pena capital. En este sentido, el Secretario de los Negocios del Reino, Sebastián José de Carvalho e Melo, conde de Oeiras y futuro marqués de Pombal, había dispuesto en la ley de expulsión de 3 de septiembre de 1759 , la prohibición de toda comunicación, verbal o escrita, de los súbditos portugueses con jesuitas, tanto con los que estaban encarcelados como con los exiliados 9 . No obstante, muchos súbditos, pese a incurrir en delito y arriesgarse a un penoso castigo, se implicaron en aliviar la penuria de los jesuitas y se ofrecieron a ser los portadores de sus escritos.

5. Azeitão era la casa del campo del duque de Aveiro que fue habilitada como prisión, tras la confiscación de sus bienes por su participación en el atentado fallido contra José I, el 3 de septiembre de 1758. En Archivo General de Simancas, sección Estado, en adelante A. G. S. Estado. Leg. 7.263. Conde de Maceda a Ricardo Wall. Lisboa, 18 de septiembre de 1759.

6. La biografía más reciente del reinado puede consultarse en Monteiro, Nuno Gonçalo: D. José. Na sombra de Pombal. Temas e Debates, Lisboa, 2008.

7. En el Archivo Campomanes de Madrid, en adelante: A.C. Leg. 41/4. Esteban Guarda al P. Cornejo, Barcelona, 27 de marzo de 1765. El abogado Esteban de la Guarda firmaba como «hermano de la Compañía de Jesús, Santa en su Instituto, en sus fines y en sus medios».

8. Martínez Naranjo, Francisco Javier: «Los invisibles jesuitas: La ofensiva contra las congregaciones marianas durante la campaña antijesuítica del setecientos», en MARTínez FERnÁNDEZ, José Enrique, y Álvarez Méndez, Natalia (Coords.) El Mundo del Padre Isla. Secretariado de Publicaciones de la Universidad de León, León, 2005, pp. 217-228.

9. Ley de Expulsión de la Compañía de Jesús, 3 de septiembre de 1759. 
Muchas de las cartas clandestinas que salieron de los presidios portugueses fueron enviadas a España, para ser remitidas a sus destinatarios; una realidad que el embajador portugués en Roma, Francisco de Almada e Mendoça, denunciaba a Lisboa al informar que los jesuitas portugueses recibían todas las semanas cartas procedentes de Portugal y que la mayoría de estos correos partían de varios lugares de España ${ }^{10}$. Sobre esta cuestión, la Asistencia española tuvo una destacada intervención, pues fue una de las más solidarias y comprometidas- favorecida además por la proximidad geográficacon la causa de sus hermanos portugueses. En consecuencia, algunos jesuitas españoles fueron los intermediarios que hicieron posible la circulación de la correspondencia entre los regulares encarcelados en Portugal con los jesuitas exiliados y con la jerarquía de la Orden en Roma.

Un aspecto importante que ofrece esta correspondencia clandestina fue que los jesuitas, a pesar de la incomunicación y vigilancia, consiguieron obtener noticias de lo que acontecía fuera de los muros carcelarios; en concreto, aquellas informaciones respecto a su Orden y la obsesión de dar a conocer el número de jesuitas que se hallaban encarcelados. En abril de 1764, los jesuitas recluidos en Azeitão pudieron enviar algunas cartas al rector del colegio de Badajoz, el P. Juan Bautista Serrano ${ }^{11}$. El P. Luis Barreto, procedente de Maranhão, escribía para conocer la suerte de los correligionarios franceses, involucrados en el proceso que acabaría con la disolución de la Compañía ese mismo año ${ }^{12}$. También esperaba noticias de si algún «príncipe nos patrocina» o cómo se había desarrollado las conquistas de los contendientes implicados en la Guerra de los Siete Años, en concreto, el enfrentamiento entre España y Portugal de 1762. Aunque la mayor expectativa del P. Barreto era conocer el impacto que había causado en Roma y en el resto de Europa la sentencia y ejecución del P. Malagrida ${ }^{13}$. En su relato, el P. Barreto aludía a las duras condiciones a las que tenían que hacer frente, como eran los rigores del invierno, y solicitaba al P. Serrano que entregase al correo una capota, aunque fuera vieja, y un poco de tabaco. A propósito del correo, el P. Barreto señalaba la caridad del sujeto, que consciente de la pobreza de los padres, se había ofrecido libremente a esta misión, un acto muy valorado por el P. Barreto; de ahí

10. En el Instituto dos Arquivos Nacionais/Torre do Tombo de Lisboa, sección Ministério dos Negócios Eclesiásticos e da Justiça, fondo Papeis Pombalinos, en adelante: IAN/TT. M.N.E.J. Papeis Pombalinos. Cx. 42, Mç. 52. Doc. 3. Francisco de Almada a Pombal. Roma, 8 de noviembre de 1759.

11. Sacerdote y Rector del Colegio de Badajoz, Provincia de Toledo. Nacido el 12 enero de 1722. Jesuita desde el 11 de marzo de 1738. Profeso de Cuarto Voto desde 1755. Embarcado en Cartagena en la fragata inglesa San Jorge el 9 de octubre de 1767 para Córcega. Residente en Forli en 1771. Residente en Rávena en 1773. Agradecemos estos datos al profesor Enrique Giménez López.

12. Para conocer el proceso contra los jesuitas en Francia véase VAN KLEY, Dale: The Jansenists and the Expulsion of the Jesuits from France, 1757-1765. Yale University Press, New Haven and London, 1975.

13. Gabriel Malagrida fue uno de los jesuitas acusados explícitamente de haber sido uno de los instigadores del frustrado atentado contra José I, el 3 de septiembre de 1758. Tras su encarcelamiento, fue el único regular ejecutado el 21 de septiembre de 1761, si bien no fue procesado como reo de crimen de lesamajestad, sino por hereje por el tribunal de la Inquisición. 
que solicitase la máxima cautela al padre rector y que se hiciese cargo de compensar económicamente al correo ${ }^{14}$.

La importancia de la lealtad de los correos era vital para poder seguir manteniendo un vínculo con el exterior, que unido a la complejidad de conseguir los utensilios necesarios para redactar las cartas y su salida al exterior, explicaba que varios ignacianos escribieran al padre rector del colegio de Badajoz en la misma carta para optimizar el esfuerzo. En esta misiva, con múltiples remitentes, el P. Manuel de Figuereido ${ }^{15}$ ponía en conocimiento que eran cuarenta y seis los ignacianos recluidos en Azeitão y que los detalles de sus condiciones de vida les serían narrados por el portador, ya que había que priorizar las necesidades y, a juicio del P. Figuereido, lo imperativo era tener noticias acerca de la situación de los jesuitas portugueses en Roma; por lo que estaban haciendo al respecto el papa, Clemente XIII, y el P. General, Lorenzo Ricci; y, sobre todo, si el rey Católico o cualquier otro príncipe se habían pronunciado en su defensa. El P. Antonio Rodrigues centró su relato en recopilar el número de fallecimientos, que ascendía a veintidós, y en realizar el recuento de los religiosos según su provincia de origen. El P. Alexandre Botelho escribía en nombre del hermano Juan Ferreyra para que algún ignaciano de la vice-provincia de Maranhão se pusiera en contacto con él y que las cartas fueran dirigidas al Colegio de Badajoz. Podemos entender el grado de desesperación que encerraba esta súplica, pues era una forma de sobrellevar con mayor entereza el cautiverio, sabiendo que en el exterior había personas preocupados por su destino, lo que explicaría también la rogativa del P. Barreto para que los jesuitas exiliados, los de Badajoz y el Santo Padre tuvieran presentes en sus oraciones a los que se habían quedado en Portugal, para que pudieran tener «la paciencia para sufrir las miserias y necesidades con que pasamos en esta prisión» ${ }^{16}$.

Los jesuitas, pese a las penurias que sufrían, intentaron preservar la jerarquía ignaciana dentro de los presidios, pues era una forma de mantenerse unidos y reforzar sus señas de identidad para combatir y hacer más llevadero el ostracismo al que el ministerio pombalino les había relegado. Tanto es así que, en mayo de 1766, los ignacianos recluidos en Azeitão decidieron solicitar al P. General la elección de un superior

14. ARSI. Lus. 87. P. Luis Barreto al Padre Rector de Badajoz. Azeitão, 24 de abril de 1764, fol. 371006/007.

15. Manuel de Figuereido, ingresó en el noviciado de Coimbra y estudió leyes en Salamanca, permaneció en la provincia portuguesa hasta 1746. Biblioteca Nacional de Portugal, en adelante B. N. P. Monografia Geral, R. 31491//6. P. Catalogo dos sogeitos que entrarão en a Companhia de Jesús na Provincia de Portugal, p. 138. Según el diarista Caeiro, Manuel Figuereido fue expulsado de la provincia de Goa, tras su llegada a Lisboa, en mayo de 1761, fue encarcelado en Azeitão. En CAEIRo, Jose: História da Expulsão da Companhia de Jesus da Província de Portugal (século XVIII), Vol. III, Editorial Verbo, Lisboa, 1999, p. 380.

16. ARSI, Lus. 87. P. Manuel de Figureido, P. Antonio Rodrigues, P. Alexandre Botelho y P. Luis Barreto al P. Rector de Badajoz. Azeitão, 23 de abril de 1764, fol. 371-008. 
que los gobernase ${ }^{17}$, la respuesta de Ricci, fechada el 15 de septiembre de $1766^{18}$, fue designar al P. Julio Pereira ${ }^{19}$.

La salida clandestina de estas y otras epístolas desde la cárcel de Azeitão fue posible gracias a la colaboración de un mozo gallego, que trabajaba en las cocinas del presidio, que se ofreció a llevar las misivas al rector del colegio de Badajoz, el P. Serrano, para que desde allí fueran enviadas con más seguridad a Roma ${ }^{20}$. De tal forma que en otros mensajes se informaba acerca de quiénes eran los jesuitas que se encontraban en la cárcel de Azeitão ${ }^{21}$, de los que perecieron durante el cautiverio ${ }^{22} \mathrm{o}$ las angustias y enfermedades que sufrían algunos de ellos ${ }^{23}$. Sin embargo, esta fructífera correspondencia quedó cercenada cuando en España se pusieron en marcha los mecanismos que acabaron con la expulsión de los jesuitas españoles. Entre los instrumentos represivos destacó la confiscación de las cartas que enviaban y recibían los jesuitas españoles, entre ellas se encontraban las misivas latinas remitidas por el General Ricci a los padres Julio Pereira y Manuel de Figuereido, ambas fechadas el 23 de marzo de 1767. Las epístolas contenían palabras de ánimo del padre General a sus hijos portugueses, en la dirigida al padre Pereira, le instaba a tener «paciencia en los trabajos y en las aflicciones que les daban algunos socios, cuya debilidad debía animar [...] y que Dios los recompensaría abundantemente de tantos sufrimientos» ${ }^{24}$.

Por tanto, estas cartas nunca llegaron a su destino, pero sí las consecuencias, ya que en virtud de la colaboración que surgió entre las cortes de España y Portugal contra la Compañía de Jesús en 1767, el gobierno de Madrid comunicó al embajador portu-

17. Ibídem. P. Manuel Figuereido al P. Francisco Pessoa. cárcel de Azeitao, 3 de mayo de 1766, fols., 356357.

18. Ibídem. P. Julio Pereira a P. Lorenzo Ricci, cárcel de Azeitão, 6 de enero de 1767, fols. 360-362v.

19. Nació el 9 de agosto de 1698 en Lisboa, donde ingresó en la Orden el 15 de febrero de 1715. Entre 1741 y 1745 fue rector del colegio de Nuestra Señora de la Luz de la Ciudad de San Luís de Maranhão. Posteriormente, entre 1748 y 1751, fue rector del Colegio de San Alexandre de Pará. Más tarde, fue elegido vice-provincial del Maranhão, de 1757 hasta 1760, en el momento de la expulsión general. Del colegio maranense fue encerrado en la cárcel de Azeitão durante seis años y después fue trasladado a Pedrouços, donde fue confinado hasta su muerte en 1775. En LeIte, Serafím: História da Companhia de Jesús no Brasil, Lisboa-Barra de Janeiro, 1938-1950, T. III, pp. 132 y 232; T.IV, pp. 231-232, 321-232 y 364 .

20. En B. N. P, Códice 7997, KAulen, Lorenzo: Relação de algumas causas que succederão aos religiosos da Companhia de Jesus no reyno de Portugal, nas suas prisões, desterros e carceres, em que estiverão por tempo de 18 annos, isto he do anno 1759 athe o anno 1777, no reinado del Rey D. Jose I sendo Primeiro Ministro... Marquez do Pombal (1784), pp. 290-291. El original está en portugués, pero los fragmentos que hemos incluido para este artículo hemos optado por su traducción al castellano.

21. ARSI, Lus. 87. P. Manuel Figuereido al P. Francisco Pessoa, cárcel de Azeitão, 3 de mayo de 1766, fols., 356-357.

22. Ibídem. P. Manuel Figuereido al P. Francisco Pessoa, cárcel de Azeitão, 30 de agosto de 1766, fols., $358-359 \mathrm{v}$.

23. Ibídem. P. Manuel Figuereido al P. Lorenzo Ricci, cárcel de Azeitão, 21 de noviembre de 1766, fols., 359.

24. En el Instituto dos Arquivos Nacionais/ Torre do Tombo, sección Ministério dos Negócios Estrangeiros, en adelante IAN/TT. M.N.E. Cx. 624. Aires de Sá e Melo a Pombal. Madrid, 24 de abril de 1767. 
gués, Aires de Sá e Melo, la existencia de estas epístolas en marzo de 1767. La reacción pombalina no se hizo esperar y los jesuitas de Azeitão sufrieron, el 7 de mayo de 1767, uno de los más humillantes registros, de sus celdas y personas:

«Después con toda la minuciosidad los palparon por todo el cuerpo, incluso en los límites de la honestidad. De tal forma que algunos tuvieron vergüenza de contar la indecencia con que los trataron, y a mí, que escribo esta relación, me contó uno que ya no está en estos reinos, que a él y a otros padres les metieron los dedos por dentro del cuerpo; y que quejándose uno de ellos porque no quería quitarse la camisa, les dijeron los oficiales que eran hombres como los demás y que ellos habían visto a muchos hombres desnudos» ${ }^{25}$.

Además, el embajador español en Lisboa, marqués de Almodóvar, informaba que habían trasladado a varios jesuitas a otros lugares de confinamiento, acusados de mantener correspondencia con el P. General ${ }^{26}$; eran los jesuitas Julio Pereira y Manuel de Figuereido, que fueron transferidos a Pedrouços. Simultáneamente, la represión pombalina se extendió al resto de la población, pues el cónsul español en Lisboa informaba que, en mayo de 1767, se dieron órdenes rigurosas

«en todo Portugal para que se prenda a todo hombre sospechoso, o que titubee a las preguntas que se han mandado hacer a los transeúntes. Habiéndose interceptado o encontrado algunas cartas de correspondencia entre algunos jesuitas españoles con tres de los portugueses presos en Azeitão» ${ }^{27}$.

En relación a la comunicación clandestina que mantenían los jesuitas reclusos en Portugal, las autoridades lusas ya habían detenido y encarcelado a varias personas acusadas de colaborar y ser correos de los regulares confinados. Las detenciones eran practicadas de acuerdo a la ley regia de expulsión, de 3 de septiembre de 1759, que prohibía toda comunicación, verbal o escrita, de los súbditos portugueses con jesuitas, tanto los que estaban encarcelados como con los exiliados. No obstante, creemos que la información suministrada por la Corte española acerca de la correspondencia secreta interceptada a los regulares alentó el hostigamiento pombalino sobre el entorno de los jesuitas portugueses, con la promulgación de una ley de 28 de agosto de 1767 que, entre otras disposiciones, castigaba a aquellos individuos que mantuvieran comunicación o auxiliasen a los jesuitas, bien expulsados, encarcelados u ocultos, con penas de destierro durante ocho años en cualquiera de los presidios de Angola, si bien las penas podían endurecerse según el alcance del delito ${ }^{28}$. Por tanto, en virtud de dicha ley, la pena impuesta a algunos de esos mensajeros de los regulares, hombres y mujeres, con-

25. Kaulen, L.: Ob. Cit., pp. 290.

26. En el Archivo Histórico Nacional de Madrid, en adelante: A. H. N. Estado. Leg. 4.536. Almodóvar a Grimaldi. Lisboa, 12 de mayo de 1767.

27. A.G.S. Estado. leg. 7.291. Agustín Sánchez Cabello a Grimaldi. Lisboa, 12 de mayo de 1767. Citado por Pradells Nadal, Jesús: Diplomacia y Comercio. La expansión consular española en el siglo XVIII. Instituto de Cultura Juan Gil Albert, Alicante, 1992, p. 369.

28. Artículo 11 de la Ley de 28 de agosto de 1767. 
sistió en el encarcelamiento, deportación a Angola o galeras, por un espacio temporal que comprendía desde los cinco años a la cadena perpetua ${ }^{29}$.

La actividad represora de la monarquía católica sobre los jesuitas españoles, antes de su expulsión, a través de la interceptación de su correspondencia, ofreció una nueva información sobre los epistolarios clandestinos procedentes de jesuitas encarcelados por Pombal; de esta manera fueron a parar a manos del fiscal del Consejo de Castilla, Pedro Rodríguez de Campomanes, varias cartas latinas escritas por el P. José Unger $^{30}$. Las misivas fueron escritas durante su reclusión en el monasterio benedictino de Montserrate, en Río de Janeiro, y estaban dirigidas a varios miembros de su Orden, fechadas entre 1765 y $1766^{31}$. Algunas de las epístolas relataban los sucesos que Unger, como misionero en las reducciones de Paraguay, vivió durante el traslado de los indios a tierras españolas por el Tratado de Límites de 1750 y la posterior sublevación indígena. Unger fue detenido por una patrulla portuguesa y llevado a Río de Janeiro, donde fue recluido por su condición de jesuita. Entre las cartas que envió el P. Unger destaca la dirigida al P. Pollerter, coadjutor senior en la ciudad bohemia de Eger, fechada el 1 de mayo de 1766, donde solicitaba su intervención para «alivio de su prisión». Sin embargo, la petición de socorro nunca llegaría a su destino, pues las cartas fueron interceptadas en Madrid y el P. Unger fue llevado a Lisboa, donde permaneció en la cárcel pública de Belem hasta su liberación en $1777^{32}$.

Llama la atención como estos religiosos encarcelados pudieron burlar la estrecha vigilancia a la que estaban sometidos y a las inspecciones periódicas e intempestivas de las que eran objeto por parte de sus carceleros y poder hacer acopio de papel y tinta para escribir sus cartas, pues los registros se practicaban de forma continua desde el momento en que entraban en prisión, tal y como relató el oficial superior de la fortaleza de Almeida, Manuel Freire de Andrade, a Pombal, el 27 de noviembre de 1759:

«la misma noche que fueron entrando [los jesuitas] en las cárceles ordené hacer una búsqueda general y se le hallaron varios papeles que traían cosidos por varias partes de las sotanas y vestidos y todavía en los interiores, que algunos con repugnancia consistieron que se los quitásemos».

29. IAN/TT. M.N.E.J. Papeis Pombalinos. Maço 65, Cx. 53, $\mathrm{n}^{\circ} 4$, Procesos de la Junta de Inconfidencia. Las penas a ocho reos acusados de ser correos de los jesuitas fueron emitidas en una sentencia dictada el 1 de febrero de 1768 .

30. Nació en Eger, el 24 de marzo de 1717. En 1748 formó parte de una expedición de misioneros europeos para las misiones guaraníes solicitada por el procurador de la Provincia de Paraguay. El P. Unger se hizo cargo de la dirección de la misión de Santa Rosa; entre 1749 y 1757, fue cura de la reducción de Loreto, hasta que en un ataque de bandeirantes fue apresado y llevado prisionero a la isla de las Serpientes. Desde allí fue enviado a Lisboa, y prisionero en la cárcel pública de Belem hasta su liberación, en 1777.

31. A.C. legajo 41/38. P. Unger al P. Lorenzo Ricci, Monasterio benedictino de Montserrate, Rio de Janeiro, 4 de octubre de 1765. A.C. leg. 41/35. P. Unger al P. Juan Cristofomo Pollerter, Monasterio benedictino de Montserrate, Rio de Janeiro, 1 de mayo de 1766 y P. Unger al P. Juan Ignacio Wedlinger, Monasterio benedictino de Montserrate, Rio de Janeiro, 24 de junio de 1766.

32. Cfr., según el relato del P. Kaulen, Unger permaneció en Belem durante 15 años, es decir, desde 1762. Kaulen, L.: Ob. Cit., pp. 202-203. 
También se aplicó la misma minuciosidad con la revisión de sus hatos y baúles, buscando cualquier escrito o papel, para luego ser remitidos a Pombal para su examen $^{33}$. En las relaciones de objetos y dinero confiscados a los regulares destaca la aprehensión, entre otros, de tinteros, lápices, libros y cajas de papeles ${ }^{34}$. Sin embargo, los regulares se buscaron las mañas para hacerse con más libros, papeles y tintas, como reseñó el P. Anselmo Eckart, mencionando un registro que sufrió en 1761:

«estaba yo el primero de diciembre bien descuidado en mi cárcel cuando oigo que, de repente y fuera de tiempo, abren las puertas y entran tres oficiales [...] a un registro general de todas mis alhajuelas. Encontraron con un poco de tinta de la China que había salvado yo de los asaltos precedentes en una cestilla chinesca muy aseada: tinta y cesta me arrebataron como también cuanto papel y escritos pudieron encontrar contando en esto estampas, imágenes y libros que eran el único consuelo en mi triste soledad» ${ }^{35}$.

Las artes para conseguir esos materiales imprescindibles para poder comunicarse los regulares recluidos, entre ellos y con el exterior, han sido referidas en el diario del P. Lorenzo Kaulen. Según el relato del diarista alemán, con el paso de los años consiguieron que, por compasión, algunos mozos que trabajaban en el presidio les llevasen libros, papeles y carbón molido para hacer la tinta. Además, el P. Kaulen reseñó que los jesuitas encarcelados contaron con la complicidad de algunos carceleros, que se dejaron sobornar, porque el «dinero todo lo puede» ${ }^{36}$, lo que explicaría la salida al exterior de parte de la correspondencia clandestina y la introducción en los presidios de objetos que aliviasen la penosa situación de los presos.

Además de la colaboración como enlaces en la remisión de los escritos de sus hermanos portugueses, los jesuitas de la Asistencia española tampoco escatimaron recursos económicos para sostener a sus cofrades en el destierro italiano, pues el gobierno portugués les había expelido como proscritos y desnaturalizados de Portugal, desatendiéndose en todos los aspectos de los jesuitas portugueses exiliados. Por tanto, si el realojo de los expulsos en Roma supuso un gran esfuerzo para la Compañía de Jesús, la manutención diaria de más de um millar de regulares presentaba un reto aún más complicado. En un principio, la Orden se hizo cargo de los gastos económicos; sin embargo, en previsión de su alto coste, la jerarquia ignaciana decidió solicitar ayuda económica al papa, bajo la fórmula de pedir licencia pontificia para que los jesuitas portugueses pudiesen recibir estipendios de misas. Sin embargo, el P. Antonio Timoni,

33. Manuel Freire de Andrade a Pombal. Almeida, 27 de noviembre de 1759, oficio trascrito en Ferrão, Antonio: «O marqués de Pombal e a expulsao dos jesuitas, 1759», en Boletim da segunda classe da Academia das ciencias de Lisboa, Vol. XVIII, (1932), pp. 539-542.

34. Ibídem, pp. 544-551.

35. Archivo Histórico de Loyola (A.H.L.), Escritos de jesuitas del s. XVIII, estante 5. Manuel LuENGO: Colección de Papeles Varios T. XXV, diario del P. Anselmo Eckart, titulado Historia de la persecución, p. 274. Sobre la traducción al castellano de este diario se puede consultar el artículo de FERNÁNDEZ Arrillaga, Inmaculada: «Deportação do Brasil e prisão nos cárceres portugueses de um jesuíta alemão: o P. Anselmo Eckart», Brotéria, Lisboa (febrero 2003), pp. 171-187.

36. Kaulen, L.: Ob. Cit., pp. 142-144. 
Secretario de la Compañía, no aceptó esta sugerencia, y el P. Ricci apoyó esta decisión hasta la muerte de Timoni, en julio de 1761, cuando cambió su postura por hacerse insostenible el gasto para mantener a los exilados ${ }^{37}$.

A partir de ese momento, los jesuitas lusos subsistieron gracias al pago de estipendios por misas y a la limosna de la Cámara Apostólica, pues siguiendo el relato del exilio del diarista castellano Manuel Luengo:

«Compadecido el Pontífice difunto Clemente XIII de los pobres jesuitas portugueses desterrados de su patria y sin pensión alguna para mantenerse, y al mismo tiempo de la Compañía, a quien era forzoso sustentar tantos centenares de hombres, ordenó que cada año se pasase de limosna al P. General por la Reverenda Cámara para el dicho efecto la suma de 4.000 ó 5.000 mil escudos. No puedo decir el tiempo en que empezó esta limosna del Papa a la Compañía, aunque con alguna probabilidad me inclino a creer que empezase cuando fuimos nosotros desterrados de España, pues con nuestro destierro perdió el P. General todo lo que se enviaba de todas las Provincias españolas para socorro de los portugueses, que no era poco» ${ }^{38}$.

Efectivamente, la Asistencia española fue la más solidaría con sus hermanos portugueses y antes de su expulsión de los dominios de Carlos III, enviaban anualmente a Roma 21.000 escudos para la manutención de sus hermanos portugueses. Según Campomanes, el 4 de abril de 1766 se enviaron en la fragata Nuestra Señora del Coro 7.642 pesos por cuenta de la provincia de Santa Fe; y el P. Gervasoni había girado una letra de 6.000 pesos contra el procurador de esa misma provincia en Madrid, ambas cantidades destinadas al mantenimiento de los jesuitas portugueses ${ }^{39}$. En este sentido, el investigador Antonio Luis López Martínez ha registrado hasta tres testimonios de envío de dinero en 1766 para el socorro de los jesuitas lusos ${ }^{40}$. Una contribución que se veía incrementada con los

«socorros de los obispos, sus parciales y apasionados, que eran el Córdoba, Granada Coria, Cuenca, Huesca, Tarragona y el de Barcelona inmediato antecesor al presente y que los caudales venían por Génova y dirección de los PP. Celli y Gervasoni, de que siempre se han servido para sus tráficos, comercios y giros con España y que para estas tenían también conducto por Holanda $»^{41}$.

37. Antonio Timoni, (1690-1761), tras su etapa de docente, desempeñó cargos en la jerarquía, entre los que destacó como provincial de Roma (1748-1751), viceprepósito de la casa profesa de Roma y, desde 1756, procurador general. A la muerte del P. General Luis Centurione (2 octubre 1757), quedó de vicario general, por designación de Centurione. Cuando Lorenzo Ricci fue elegido general (21 mayo 1758), Timoni le sucedió como secretario de la Orden. O’Neill, Charles y Domínguez, Joaquín: Diccionario Histórico de la Compañia de Jesús, I.H.S.I. - Universidad de Comillas, Roma - Madrid, 2001,Vol. IV, p. 3.803.

38. A.H.L, Escritos de jesuitas del s. XVIII, estante 5, Luengo, Manuel: Diario, T. VI (1772), pp. 416-417.

39. Rodríguez de Campomanes, Pedro: Dictamen fiscal de expulsión de los jesuitas de España (17661767). Edición, introducción y notas de Jorge Cejudo y Teófanes Egido, Madrid, 1977, p. 119.

40. López Martínez, Antonio Luis: «Los jesuitas y el tráfico de dinero en la carrera de Indias (1753-1767)». En Cuadernos de Investigación Histórica, no 14, (1991), pp. 7-23, en p. 18.

41. A.G.S. Estado. Leg. 5.046. José Nicolás de Azara a Grimaldi. Roma, 10 de marzo de 1768. 
El seguimiento de la política antijesuítica portuguesa causó una gran expectación en España, un interés compartido tanto por los jesuitas españoles, preocupados por el destino de sus hermanos y en recopilar toda la información y la legislación portuguesa que se publicaba para fundamentar sus réplicas; como por los cada vez más amplios círculos antijesuíticos españoles, integrados por ministros, funcionarios y eruditos ${ }^{42}$.

Uno de los instrumentos más eficaces de la política antijesuita de Pombal fue la de orquestar una formidable campaña de desprestigio de la Compañía auspiciando la impresión y difusión de una vasta literatura antijesuita por toda Europa ${ }^{43}$. La primera pieza de este engranaje fue la Relación Abreviada, editada en Lisboa a finales de 1757. La traducción castellana de la Relación Abreviada apareció el mismo año que la original, en 1757. La intención de Pombal de incluir a los jesuitas de la Asistencia española era manifiesta, pues deseaba que la monarquía hispánica descubriera la nefasta influencia de la Orden y cambiara su actitud de protector a la de perseguidor. Así, a mediados de marzo de 1758, el embajador portugués Antonio Saldanha fue el encargado de intoxicar a Fernando VI y a su gobierno sobre los desórdenes cometidos por los regulares en las misiones, cuyas pruebas estaban contenidas en el opúsculo pombalino.

Si bien el Secretario de Estado, Ricardo Wall ${ }^{44}$, adscrito a la corriente antijesuita, era un admirador de la política portuguesa, los jesuitas españoles contaban con importantes influencias en la Corte que no dudaron en ponerse al servicio de la defensa de la Compañía de Jesús y minimizar los ataques procedentes del antijesuitismo portugués.

Por ejemplo, el embajador António Saldanha informó a Lisboa que había frustrado dos estrategias que atribuyó a los jesuitas para infiltrar a sus agentes en la embajada portuguesa y poder así recabar información del ministerio pombalino. El diplomático relató que a la embajada solicitó audiencia un hombre que afirmaba ser muy influyente y que poseía importantes conocimientos estratégicos acerca de los dominios españoles en América, por lo que ofrecía sus servicios a la corona portuguesa. Saldanha no valoró el ofrecimiento y lo despidió con «severidade». El principal Saldanha inició las pesquisas para conocer la identidad de este sujeto y averiguó que era un hombre «opulento» muy relacionado con los ministros del Consejo de Indias y, por ende, también con los jesuitas y con el gobernador del Consejo de Castilla.

42. Véase: Gimenez LóPEz, Enrique: «El antijesuitismo en la España de mediados del siglo XVIII». En Fernández Albadelejo, Pablo (ed.): Fénix de España. Modernidad y cultura propia en la España del siglo XVIII (1737-1766). Homenaje a Antonio Mestre Sanchís. Marcial Pons, Universidad Autónoma de Madrid, Universidad de Alicante y Casa Velázquez. Madrid, 2006, pp. 283-326 y Garcia Arenas, Mar: «La proyección del antijesuitismo portugués en España (1758-1762)». En MarTínez MiLláN, José; Pizarro Llorente, Henar y Jiménez Pablo, Esther: Los jesuitas: Religión, política y educación (siglos XVI-XVIII), Vol. III. Universidad Pontificia Comillas, Madrid, 2012, pp. 1.811-1.842.

43. Sobre su impacto e influencia en Italia es imprescindible el estudio de VeNTURI, Franco: Settecento riformatore. Vol. II: La Chiesa e la republica dentro i loro limite, 1758-1774. Turín, 1974.

44. Tellez Alarcia, Diego: D. Ricardo Wall. Aut Caesar aut nullus. Ministerio de Defensa, Madrid, 2008. 
Otra persona que consideró un emisario de los jesuitas fue el marqués de San Antonio, que se había presentado en la embajada a los pocos días de llegar Saldanha a Madrid, alegando que eran parientes lejanos ${ }^{45}$. El noble ofreció sus servicios al diplomático y le informó que no contaba con las simpatías de Fernando VI, desde la caída en 1754 del marqués de la Ensenada, ya que era una de las «creaturas» del defenestrado ministro. Saldanha no sospechó del marqués de san Antonio, pues regularmente dejaba notas de salutación en la embajada, aunque sin solicitar nunca una audiencia con el embajador. Sin embargo, poco después del suceso con el confidente del Consejo de Indias, el aristócrata demandó una entrevista donde ofreció al embajador prestarle el dinero que necesitara «sem menor interesse», pero Saldanha declinó amablemente su oferta $^{46}$.

La literatura antijesuítica que circulaba en España se había multiplicado desde la caída del confesor regio, el jesuita Rávago en 1755. Además, tanto la legación portuguesa en Madrid como la propia Secretaria de Estado, que recibía las obras a través del embajador español en Lisboa ${ }^{47}$, eran centros difusores de los ejemplares antijesuíticos portugueses en España. Aunque en un principio la jerarquía ignaciana prohibió a sus miembros la refutación a los panfletos portugueses, esta inicial autocensura fue insostenible ante el evidente clima político adverso a la Compañía de Jesús, por lo que los religiosos y sus simpatizantes aunaron sus esfuerzos para minimizar los envites que recibían de las decisiones y de la literatura propagandística pombalina, si bien la mayoría apareció de forma anónima, bajo el formato de epístolas u opúsculos. No se escatimaron esfuerzos y muchas de las obras salieron de las imprentas de los propios colegios y casas de la Compañía ${ }^{48}$; además, hubo algunos particulares, como el caso del abogado barcelonés Esteban Guarda, que sufragaron el coste de la publicación; en otras ocasiones «se han costeado de dineros de jesuitas o de sus aficionados» e incluso se llegó al paradójico caso de llevarse a cabo la impresión de obras pro-jesuitas, como fueron las constituciones de la Compañía, financiadas con «dineros de contrarios de los jesuitas que por haber temerariamente pleiteado contra un colegio han salido condenados a costas y ésta victoria sirvió para ganar la impresión $\rangle^{49}$.

Aunque la indignación del embajador Saldanha creció ante la temeridad de los jesuitas cuando consiguieron que se ordenase la incautación de los ejemplares del

45. Buena parte de los principales linajes portugueses eran de origen castellano como Castro, Hurtado de Mendoza, Lima o los Saldañas. En Monteiro, Nuno Gonçalo: «Nobleza y élites en el Portugal Moderno en el contexto de la península Ibérica (siglos XVII y XVIII)». En SorIa Mesa, Enrique; Bravo Caro, Juan Jesús y Delgado Barrado, José Miguel (Eds.): Las élites en la Época Moderna: La monarquía española. Vol. I. Nuevas Perspectivas. Servicio de Publicaciones Universidad de Córdoba, Córdoba, 2009, pp. 143-155, p. 143.

46. IAN/TT. M. N. E. Cx.622. Antonio Saldanha a Luis da Cunha. Madrid, 4 de abril de 1758.

47. A.G.S. Estado. Leg. 7. 264. Ricardo Wall al conde de Maceda. Villaviciosa, 2 de agosto de 1759.

48. BARTOlomé Martínez, Bernabé: «Las librerías e imprentas de los jesuitas (1540-1767): Una aportación notable a la cultura española». En Hispania Sacra, (enero-junio 1988), pp. 315-388.

49. A.C. Leg. 41/4. Esteban Guarda al P. Cornejo, Barcelona, 27 de marzo de 1765. 
Mercurio Histórico y Político $^{50}$ del mes de septiembre de 1759 que contenía la noticia de la ley de expulsión de los jesuitas de los dominios portugueses, aduciendo que el número debía reimprimirse. Tras el decomiso, se volvió a reimprimir el periódico aunque sin mencionar el decreto de desnaturalización de los ignacianos portugueses ${ }^{51}$. Efectivamente, los ejemplares del Mercurio relativos a las noticias de Lisboa del mes de septiembre de 1759 presentan una omisión de ocho páginas y no hay referencias a la referida $l e{ }^{52}$.

Saldanha se empleó en resolver el origen de esta decisión, pues los rumores atribuían la orden a la reina madre, Isabel de Farnesio, simpatizante de la Compañía. El embajador tuvo constancia que una dama de la reina, la condesa de Cerbellón ${ }^{53}$, cuyo confesor era jesuita, había aconsejado a la reina que tal vez la ley había sido mal traducida por los «émulos» de los antijesuitas españoles, por tanto no era prudente que se difundiera de tal forma por toda Europa; de ahí que era necesario cerciorarse del contenido de la traducción a la espera de la llegada de Carlos III. El resultado fue que se dio la orden de reimprimir el Mercurio sin la ley de expulsión hasta que se examinase su traducción. Cuando Ricardo Wall se enteró de esta decisión la acató, aunque comentó que la reina madre «não esta bem informada» y esperaba que la ley apareciera en el Mercurio del mes siguiente, en octubre ${ }^{54}$, si bien la ley de expulsión fue finalmente incluida en el mes de diciembre de $1759^{55}$.

Cuando Saldanha fue hablar con Wall acerca de este asunto, el Secretario de Estado le confesó que no se opuso a la orden de decomisar los ejemplares del Mercurio, pues consideró que sería una oportunidad inmejorable de indisponer a Carlos III contra los regulares, una vez tuviera conocimiento de lo sucedido. Wall insistió en asegurar al embajador portugués que la ley de expulsión aparecería en el Mercurio del mes siguiente, que para Saldanha era una manera de «moderar o meu disgusto» ${ }^{56}$. No obstante, esta situación no fue un caso aislado, ya que los golpes de fuerza de Pombal contra los jesuitas no cesaron, lo que implicaba una nueva reacción de los filojesuitas.

50. La publicación del Mercurio Histórico Político dependía de la Secretaria de Estado y desde 1756 se consideraba uno de los periódicos oficiales de la monarquía española. En Enciso Recio, Luis Miguel: La Gaceta de Madrid y el Mercurio Histórico y Político, 1756-1781. Valladolid, Facultad de Filosofía y Letras, 1957, p. 20.

51. IAN/TT. M. N. E. Cx. 622. Antonio Saldanha a Luis da Cunha. Madrid, 2 de noviembre de 1759.

52. En la Biblioteca Nacional de España, en adelante: B. N. E. D-5171. Mercurio Histórico y Político, mes de septiembre de 1759, noticias de Portugal, de Lisboa, pp. 9-19.

53. Laura María de Castellví y Mercader, condesa de Cervelló y marquesa de Villatorcas, que contrajo matrimonio con don Antonio Ossorio de Guzman, teniente general de los ejércitos reales, era cuñada de Ignacio Enrique Osorio de Guzman, que desde 1758 era rector del colegio de Salamanca y el año de la expulsión acababa de ser designado provincial de Castilla. Agradecemos estos datos al profesor Enrique Giménez López.

54. IAN/TT. M. N. E. Cx. 622. Antonio Saldanha a Luis da Cunha. Madrid, 2 de noviembre de 1759.

55. B. N. E. D-5171. Mercurio Histórico y Político, mes de diciembre de 1759, noticias de Portugal, de Lisboa, pp. 346-352.

56. IAN/TT. M. N. E. Cx. 622. Antonio Saldanha a Luis da Cunha. Madrid, 3 de noviembre de 1759. 
La política pombalina suponía un desafío para el pontificado de Clemente XIII, que unido a la disolución de la Compañía en Francia en 1764, aumentó el temor en la Santa Sede que la corriente antijesuita, que cada vez contaba con más adeptos, asolase más Estados católicos, en especial a la monarquía española, no tanto por la cercanía con Portugal sino, sobre todo, por su vinculación política y cultural con Francia. La reacción pontificia fue la publicación de la bula Apostolicum Pascendi, el 7 de enero de 1765. El documento pontificio declaraba a la Compañía de Jesús como un instrumento fundamental para la labor evangelizadora de la Iglesia. La Orden de san Ignacio fue definida como cuna de santos y un elemento poderoso para inculcar el bien entre los seglares; de hecho, confirmaba la vigencia de sus ejercicios espirituales, sus devociones especiales que promovían la piedad cristiana y que las congregaciones de la Santísima Virgen eran recomendables para todos los cristianos. El problema de la bula radicaba no tanto en el aspecto laudatorio hacia los jesuitas sino en las condenas que contenía, pues señalaba que todos aquellos que hablaran o escribieran contra la Compañía incurrían en un gran error, pues era un Instituto religioso que contaba con la aprobación personal de Clemente XIII, como lo habían hecho en el pasado otros pontífices y obispos relevantes de la cristiandad. En definitiva, el mensaje que transmitía la bula era que atacar a la Compañía era agredir a la propia Iglesia y censuraba la política de Portugal y Francia ${ }^{57}$.

La postura de los jesuitas españoles fue la de traducir la bula al castellano, siendo impresa en varios centros. Además, varios centenares de los ejemplares, procedentes de Sevilla y Málaga fueron enviados a Portugal ${ }^{58}$. También desde el Colegio Imperial de Madrid se enviaron varias copias al Colegio de Badajoz para que el padre Rector, Juan Bautista Serrano, las difundiera en el reino vecino ${ }^{59}$.

Ante esta ofensiva pro-jesuita, la respuesta de Lisboa fue que el 15 de mayo de 1765 se publicó la Petiçao de recurso del Procurador General, José Seabra da Silva ${ }^{60}$, acompañada de una real cédula que prohibía tanto la publicación de la bula Apostolicum Pascendi como cualquier escrito que le hiciera referencia ${ }^{61}$. El Procurador denunciaba que los ejemplares de la bula, escritos en lengua latina y castellana, habían sido introducidos clandestinamente en el reino portugués «valiéndose del sutil y desusado medio de echar en los correos que vienen de los países extranjeros, cubiertas o sobrescritos, sin declarar de dónde vienen ni las personas que las echaron».

57. Miller, Samuel J.: Portugal and Rome, c. 1748-1830. An aspect of the Catholic Enlightement. Roma, Universitá Gregoriana Editrice, 1978, p. 142.

58. Soto Artuñedo, Wenceslao: Los jesuitas de Málaga y su expulsión en tiempos de Carlos III. Centro de Ediciones de la Diputación Provincial de Málaga, Málaga, 2004, p. 26.

59. A.C. Leg. 41/4. José Ribeiro Furtado de Mendoça al P. Cornejo. Barcelona, 13 de febrero de 1765.

60. Sobre el ascenso en la carrera administrativa de José Seabra da Silva veáse: ViLHENA, João Jardim de: «José da Seabra da Silva. A sua política e o seu destèrro». En O Instituto, Vol. 85, n 2, Coímbra, 1933, pp. 117-134.

61. A. H. N. Estado. Leg. 4. 536. Almodóvar a Grimaldi. Lisboa, 21 de mayo de 1765. Una copia de ambos documentos se halla en A. H. N. Estado. Leg. 4. 388 y B.N.P. Colecção Josephina. Cod. 454, T. II. 
La réplica del entorno filojesuita en España ante este nuevo envite del ministerio portugués fue conseguir que el traductor del Mercurio Histórico y Político impidiese la publicación íntegra del contenido de la Petição de recurso contra la bula Apostolicum Pascendi en el número de septiembre de 1765. No obstante, cuando Carlos III tuvo conocimiento del asunto, ordenó que el traductor fuese amonestado y dio instrucciones precisas a la Secretaria de Estado para que se llevase a cabo una supervisión estricta, con el fin de asegurar la inclusión de la traducción de la Petição do recurso en las noticias de Portugal en el número de octubre. Efectivamente, en las noticias de Portugal del mes de septiembre solo se hacía mención a la publicación en Lisboa de la Petição de recurso, donde el procurador de la Corona condenaba e impugnaba la bula Apostolicum Pascendi ${ }^{62}$; la traducción íntegra del pedimento fiscal apareció en dos partes, la primera en las noticias de Portugal del mes de octubre ${ }^{63}$ y la segunda en el mes de noviembre de $1765^{64}$. El embajador portugués en Madrid, Aires de Sá e Melo, tuvo constancia del hecho gracias a la confidencia que le trasmitió Pedro Estuardo ${ }^{65}$, marqués de san Leonardo ${ }^{66}$. No obstante, la beligerancia de los ignacianos no cesó pese al ambiente hostil en el que se hallaban inmersos. En este sentido, Manuel de Roda, Secretario de Gracia y Justicia, informaba al Agente de Preces en Roma, en una epístola fechada el 4 de marzo de 1766, que

«se ha impreso en España sin licencia, ni data de lugar, ni tiempo, un librito con la Bula Apostolicum y Breves de Giacomeli a la Francia, y al fin las respuestas a los Obispos de España que dieron las gracias al Papa por la dicha Bula, y son el de Ciudad Rodrigo, Coria, Barcelona, Huesca, Zamora, Oviedo, Valladolid, Teruel, Cuenca, Tarazona, Cádiz, Pamplona, Solsona y Tarragona. Las más de las cartas de los obispos se habrán escrito en el Jesús, a donde suelen venir las firmas en blanco, y las respuestas del Papa en San Ignacio por Giacomeli con acuerdo del P. Lazzari» ${ }^{67}$.

Sin embargo, la red social de apoyo a los jesuitas portugueses comenzó a resquebrajarse cuando a raíz del Motín de Esquilache los jesuitas españoles fueron señalados como los instigadores de la rebelión; y un año después, Carlos III dictaminó la Pragmática Sanción de 3 de abril de 1767 que condenaba al exilio pontificio a todos los

62. B. N. E. D-5171. Mercurio Histórico y Político. Noticias de Portugal del mes de septiembre de 1765 , pp. 85-86.

63. Ibídem. Mercurio Histórico y Político. Noticias de Portugal del mes de octubre de 1765, pp. 153-192.

64. Ibídem. Mercurio Histórico y Político. Noticias de Portugal del mes de noviembre de 1765, pp. 256-290.

65. Don Pedro Stuart, marqués de San Leonardo, alcanzó el grado de capitán general de la Armada, habiendo entrado a servir de guardiamarina en 1736. En 1764, Carlos III le concedió la gracia de usar el antiguo título de marqués de San Leonardo a instancia de su hermano el duque de Berwick. En MARQuÉS DE Velamazán: Don Pedro González de Castejón y Salazar. Marqués de González de Castejón y Salazar. Ministro de Marina de Carlos III. Colección «Temas Populares» n. ${ }^{\circ} 12$. Centro de Estudios Borjanos. Institución «Fernando el Católico». Zaragoza, 2002, p. 45.

66. IAN/TT. M.N.E. Cx. 623. Aires de Sá e Melo a Luis da Cunha. Madrid, 10 de diciembre de 1765.

67. En el Archivo Histórico de la Provincia Canónica de Toledo de la Compañía de Jesús, en Alcalá de Henares, en adelante AHPCTSI, S.I, E-1: 5,9, Leg. 739. Manuel de Roda a José Nicolás de Azara. Madrid, 4 de marzo de 1766. 
jesuitas de sus dominios ${ }^{68}$. Esta decisión cercenó el fructífero auxilio que recibían los jesuitas de sus hermanos españoles, que también emprendían el camino del destierro y unirían sus destinos en el exilio pontificio. La represión del jesuitismo ya había puesto al descubierto la relación epistolar clandestina de los jesuitas; no obstante, los réditos represivos contra los regulares fueron aún más sorprendentes cuando el gobierno español descubrió que desde Génova, el P. Carlos Gervasoni ${ }^{69}$ se había convertido en el enlace para la introducción de jesuitas portugueses en España. Una vez se informó a Lisboa de ésta trama jesuítica, la colaboración de las monarquías ibéricas contra los jesuitas dio sus frutos y dos ex-jesuitas portugueses fueron interceptados en territorio español; en contraprestación, el gabinete portugués entregó a las autoridades españolas a un jesuita español secularizado procedente de Río de Janeiro ${ }^{70}$.

El descubrimiento de estos secularizados ocultos impulsó una mayor atención y colaboración por parte de los gobiernos ibéricos en la detención de cualquier sujeto sospechoso de colaborar como agentes infiltrados de los jesuitas en los dominios de los que habían sido expelidos. Por tanto, a principios de febrero de 1768, el Secretario de Gracia y Justicia, Manuel Roda, se entrevistó con el embajador portugués, Sá e Melo, para entregarle unos documentos hallados entre los papeles del aposento del P. Francisco Xavier Cornejo, confiscados en el colegio Imperial cuando se intimó la Pragmática Sanción.

Por los documentos incautados se supo que, a principios de 1765, fray Manuel Evangelista de la Concepción, franciscano observante portugués, calificador del Santo Oficio que había sido confesor del circulo cortesano de la reina portuguesa y amigo del P. Malagrida, había huido de Portugal y entrado en España con una identidad falsa, haciéndose pasar por el presbítero José Ribeiro Furtado de Mendoça. Durante su viaje de huida, de Badajoz a Talavera, sufrió un asalto que le dejó sin recursos económicos. Ante esta contrariedad, el fraile se dirigió a Madrid y en el colegio Imperial recibió auxilio económico por parte del P. Cornejo y del P. Rector ${ }^{71}$, además de la aportación de

68. GuASTI, Niccoló: L'Esilio italiano dei gesuiti spagnoli. Identitá, controllo sociale e pratiche culturali (1767-1798). Biblioteca del XVIII Secolo. Edizioni di Storia e Letteratura. Roma, 2006.

69. Carlos Gervasoni, (1692-1773). Destinado a la provincia de Paraguay, fue rector del Colegio de San Miguel de Tucumán y ecónomo de la provincia. En 1751 fue electo procurador de la provincia de Paraguay en Roma y Madrid, donde protestó contra el Tratado de Límites, por lo que fue expulsado de España y sus dominios en febrero de 1756, siendo trasladado a la casa profesa de Génova y luego al Noviciado de la misma ciudad, donde murió. En O’Neill, C.E y Domínguez, J.M (Dir.): Ob. Cit., T. II, p. 1.720 .

70. Para conocer con detalle estos tres casos y sus consecuencias véase: GARCIA ArENAS, Mar: «La colaboración hispano-portuguesa contra la Compañía de Jesús (1767-1768)», en GimÉNEz LóPEZ, Enrique (Ed.): Aspectos de la politica religiosa en el siglo XVIII. Estudios en Homenaje a Isidoro Pinedo Iparraguirre S. J. Publicaciones de la Universidad de Alicante, Alicante, 2010, pp. 59-83.

71. Joaquín Navarro, Sacerdote y Rector del colegio Imperial de Madrid, Provincia de Toledo. Nacido el 5 de agosto de 1705. Jesuita desde el 28 de junio de 1722. Profeso de Cuarto Voto desde 1738. Catedrático de Vísperas de la Universidad de Alcalá. Embarcado el 28 de abril de 1767 en Cartagena en la Urca holandesa María Teresa rumbo a Civitavecchia. Residente en Rávena en 1773. Muerto en Forli el 26 de abril de 1780. Agradecemos estos datos al profesor Enrique Giménez López. 
un particular, Julián Bautista Orzel, que se encargaría de recibir la cantidad abonada al fraile, que dejó como garante de pago a su hermano, que era Consejero de Hacienda o desembargador en Lisboa; y en caso de que el hermano no se hiciera cargo de la deuda, el fraile había dejado la dirección de una dama de palacio como segunda garantía.

Los jesuitas, además, proporcionaron protección para que el falso presbítero José Ribeiro pudiera llegar con éxito a Roma; con tal objetivo, lo enviaron al colegio de los jesuitas de Barcelona, donde encontraría la ayuda del abogado Esteban Guarda, vinculado a la Compañía de Jesús por una carta de hermandad, que «por amor a ella [la Compañía] quiso así amparar al sujeto dicho» ${ }^{72}$. En Barcelona, el fraile solicitó pasaporte para poder embarcarse con destino a Génova al Capitán General, marqués de la Mina, que le denegó el salvoconducto. Ante este imprevisto, el abogado barcelonés le indicó que tomara la ruta por Francia «del modo que se la había yo prevenido», pues el fraile carecía de un pasaporte que le garantizase su tránsito seguro hasta Roma. Una de las paradas de ese itinerario terrestre era Bellegarde, a donde arribó el fraile el 20 de febrero de 1765 y escribió una carta a Esteban Guarda informándole que «estaba ya fuera del peligro que le podía ocasionar la falta de pasaporte». El abogado barcelonés esperaba con impaciencia que el fraile portugués hubiese llegado a Montpellier, desde donde remitiría una carta informando de los acontecimientos de su viaje, pues en palabras del abogado, su lectura sería «un gran consuelo para esta nuestra tertulia jesuítica barcelonesa». Además, en esa ciudad francesa el abogado contaba con un mercader para proporcionar ayuda económica al fugitivo, una transacción que se efectuó el 28 de febrero de 1765. Una vez abandonado territorio francés, el fraile debía dirigirse a Génova, donde había otro comerciante que le proporcionaría dinero y un pasaporte, conseguido por las gestiones del P. Cornejo en $\mathrm{Madrid}^{73}$, para seguir el viaje de forma segura hasta Roma.

Del contenido de la epístola, que el abogado Esteban de la Guarda dirigió al P. Cornejo acerca del viaje del presbítero, se deducía que los jesuitas contaban con una sólida red social que facilitaba a sus protegidos lugares seguros por donde transitar e inclusive agentes comerciales para llevar a cabo la transacción de las ayudas económicas.

Manuel de Roda comunicó esta noticia al embajador portugués porque sospechaba que el fraile franciscano podría regresar a Portugal como emisario de los jesuitas. Las pruebas que se deducían de las cartas interceptadas eran definitorias, pues el fraile había solicitado en 1765 al P. Cornejo el envío de ejemplares de la bula Apostolicum Pascendi a Badajoz para que fueran difundidas en Portugal, una tarea a la que también se dedicaría el fraile una vez llegase a Roma ${ }^{74}$ y porque tenía una valiosa información que podría ser muy útil para la Compañía, una vez se conociese en la Ciudad Eterna ${ }^{75}$.

72. A.C. Leg. 41/4. Memoria del P. Cornejo, s.f, s.l.

73. Ibídem. Esteban Guarda al P. Cornejo, Barcelona, 27 de marzo de 1765.

74. Ibídem. José Ribeiro Furtado de Mendoça al P. Cornejo. Barcelona, 13 de febrero de 1765.

75. Ibídem. Esteban Guarda al P. Cornejo, Barcelona, 27 de marzo de 1765. 
El cerco represivo sobre el entorno seglar simpatizante con la causa jesuita por parte de las autoridades gubernamentales españolas continuó, favoreciendo el intercambio de información con el ministerio portugués. Así, el mismo mes de febrero de 1768, el embajador portugués recibía una memoria del Secretario de Estado, marqués de Grimaldi, que contenía informaciones procedentes de Roma sobre la inminente llegada de un emisario de los jesuitas a España y Portugal. Se trataba de Bartolomé Pasquini, abate florentino, «de estatura más que mediano, de unos 40 años de edad, poco más o menos; más flaco que gordo; voz entre femenil y obscura; trae peluca; es corto de vista y cuando habla cierra los ojos; de color pálido, robusto de brazos y muñecas ${ }^{76}$. El embajador español en Roma, monseñor Azpuru, fue quien descubrió esta trama tras la confiscación de algunas cartas remitidas desde España para el abate José de la Torre ${ }^{77}$. Azpuru, durante la investigación de la correspondencia, descubrió que el abate Pasquini era

«tan pobre que se mantenía miserablemente con el oficio de copista del Notario y Fiscal de la Reverenda Fábrica, repentinamente había comparecido vestido con mucha propiedad, y decía que había de hacer un giro por España y Portugal, respondiendo a los que admirados le preguntaban con qué caudal se empeñaba en tan costoso viaje, que no le faltaba el preciso para hacerlo, que pasaría a Barcelona, después a Cádiz, y desde allí a Portugal».

Si bien Azpuru pudo descubrir que el supuesto espía había salido de Roma hacia el mes de octubre de 1767, «manifestando abundar de dinero para su giro, llevando para él cantidades en especie, y otras en letras de cambio», nada pudo averiguar de la correspondencia de Pasquini «con los Jesuitas de esta Corte ni con sus partidarios y amigos, y a este efecto continuó la más viva solicitud». No obstante, el embajador Azpuru reunió las suficientes pruebas que indicaban que Pasquini ya se encontraba en España, «acaso será en Barcelona, Cádiz u otra capital», por lo que era conveniente su detención ${ }^{78}$. Efectivamente, cuando Carlos III tuvo conocimiento de esta noticia se remitieron las órdenes oportunas al Consejo Extraordinario para que se llevasen a cabo «las diligencias convenientes a fin de descubrir dicho abate» ${ }^{79}$. En consecuencia, se puso en conocimiento de Pombal esta trama para que tomase las medidas oportunas para evitar que el agente de los jesuitas pudiera cumplir con su misión.

76. IAN/TT. M.N.E. Cx. 625. Aires de Sá e Melo a Pombal. Madrid, 12 de febrero de 1768.

77. Para profundizar sobre este asunto véase: MuÑoz Romero, Miguel Ángel: «Labores de espionaje del embajador Tomás Azpuru en Roma durante el primer año de exilio de los jesuitas españoles (1767)». En GimÉnEz LóPEZ, Enrique (Ed.): Aspectos de la política religiosa en el siglo XVIII. Estudios en Homenaje a Isidoro Pinedo Iparraguirre S. J. Publicaciones de la Universidad de Alicante, Alicante, 2010, pp. 85-110.

78. En el Archivo del Ministerio de Asuntos Exteriores de Madrid, en adelante A.M.AA.EE. Santa Sede. leg. 331. Azpuru al Marqués de los Llanos. Roma, 21 de enero de 1768, fols., 16-20.

79. A.G.S. Estado Leg. 5.045. Grimaldi a Azpuru. El Pardo, 9 de febrero de 1768. 